\title{
ENHANCING THE POWER OF NEGOTIATION-A DECISION MAKING PERSPECTIVE
}

\author{
DEEPIKA GAUR ${ }^{1} \&$ BHAWNA GAUR ${ }^{2}$ \\ ${ }^{1}$ Assistant Professor, American University in Emirates, Dubai, United Arab Emirates \\ ${ }^{2}$ Assistant Professor, Amity University Dubai Campus, Dubai, United Arab Emirates
}

\begin{abstract}
The need to negotiate is vital in daily chores, to reach to a consensus, for taking any decision. Despite the facts that people bring into action their negotiation skills every day, in the personal or professional lives, but hardly have they gone for any negotiation skills training. The notion of excelling in negotiation skills can lead people to bargain for some minor requirements but does not make them expert of the skills of negotiating. Every individual has a unique personality and hence the skills administered by them require the merger of their personality traits to the skill effectiveness. The proper flow of negotiation depends upon various individual and situational factors. In an organization setting employees have to negotiate as a part of their job either with outside or inside customers; however, the skill if not learned may lead to suboptimal decisions. Negotiation is a primary approach to reach to any decision when an individual, team or organization has to deal with any other party. Organizations play a large emphasis on the negotiation outcomes rather than focusing on the teaching of the skills to negotiate. However, there is a large gap in understanding the outcome of negotiation skills training. Large amount of data is focused on negotiation tactics and its outcome but lack the implementation of the skills on an individual and the training required. This research aims to place an initial platform for the need of negotiation skills training.

KEYWORDS: Negotiation Skills, Communication, Training, Information Technology \& Decision-Making
\end{abstract}

Received: Sep 12, 2017; Accepted: Oct 02, 2017; Published: Oct 28, 2017; Paper Id.: IJBMRDEC20171

\section{INTRODUCTION}

"Major public policies are the outcome of a complex round of negotiation between interests, choices between values and competition between resources... there are no single 'best' options for any player in this game, for the 'best' outcome depends on what others do and what deals are possible." (Davis et al., 1993)

Negotiation is a skill which is required to be upgraded after a time interval. This is because of the nature of negotiation which depends on skills, culture, psychology, economy and managerial perspectives. Negotiation is a prime approach in an organization to reach to any decision whenever a person, organization, or another entity cannot achieve its goal unilaterally. Negotiation is an unavoidable part of work and everyday life.

Negotiation is a tool to settle differences. It is a process to reach to compromise and agreement while avoiding argument and discomfort. Hence, in business, negotiation starts right from the place of bargaining for employee's own compensation to the discussions of projects and finalizing the deals with clients. Thus, the need of skilled negotiators is common to all industry types, so a model that inculcates the skill of negotiation in employees is of great necessity. Self help material supports the human tendency to consider themselves as skilled negotiators, but the kind of demand being fostered by organizations need employees to be well versed with the intricacies of this 
ability. This proves the importance of imparting training to employees periodically to enhance their ability to negotiate and settle the argument in right direction.

A lot of material is focused on the development of negotiation skills and suggest various tactics for the same. But, the question is how the skill could be developed, much like great leaders, some people believe (Malhotra \& Bazerman, 2007) that, great negotiators are born with the talent. However, similar to the concept of leadership, the typical definitions of negotiation (e.g., Fells, 2010; Fisher, Ury, \& Patton, 1991; Thompson, Wang, \& Gunia, 2010) suggest that, negotiation is a process that transpires between people. Just like leadership, negotiation might be developed and further honed, but the way of training is ignored. Similar to leadership skills, negotiation skills are challenging to teach, assess, and provide feedback on (Nadler, Thompson, \& Boven, 2003). Though, scholarly researchers have presented comprehensive tutorials and guides for effective negotiation (e.g., Lax \& Sebenius, 2006; Thompson, 2008; Watkins, 2002), our intent is to state and prove the importance of negotiation skills training, which can build the awareness towards the gaining of the skills from an expert.

The present research aims at not only proving the effectiveness of formal training program but also build an insight for the industry to measure the after effects of training and the utility of it for the organization. Additionally, we examine the components of negotiation skills and a comparison between the components which shows greater improvement with the effect of training. Based upon limited existing research on these issues, the proposed way of measuring the training effectiveness is an initial effort toward the creation of a more efficient framework of developing means to study the pre-post skills of employees receiving training. Thus, the hope is that the initial efforts draw the attention of future researchers to take the initiative ahead and contribute to the elaboration and expansion of the model.

\section{IT Industry - An Overview}

The term technology commonly refers to society's application of scientific knowledge to solve practical problems in industry or commerce. Technological innovation, or the application of technology, takes many forms and often involves the interplay of expertise across multiple disciplines and industry verticals. One framework for categorizing technology entails the use of five distinct groupings (Comptia, Research Report, and January, 2016).

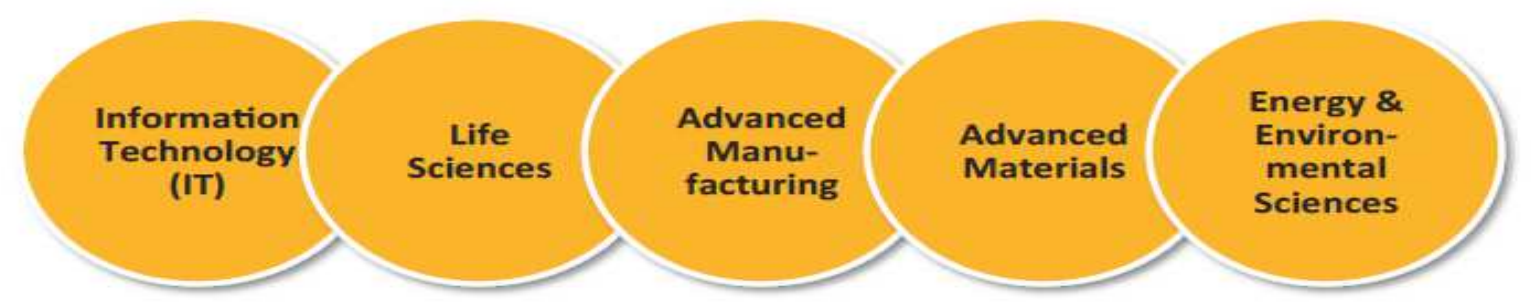

Source: https://www.comptia.org/resources/it-industry-outlook-2016-final

Each segment of this technology framework has contributed to economic growth and the well-being of society. The magnitude of advances in medicine, transportation, safety, manufacturing, agriculture, media and communication are almost difficult to comprehend.

Since the turn of the millennium though, the one segment that arguably has had the greatest impact on businesses, consumers and other industry sectors is information technology (IT). This collaboration among various professionals and customers brings in different skills of negotiation. IT industry being internationally collaborative demands association of 
different cultures and lays the burden on negotiator to associate negotiation skills applicable in different cultures in a smooth way.

\section{Growth Aspects}

According to the research consultancy IDC, the global information technology (IT) industry market, encompassing hardware, software, services, and telecommunications, was expected to reach $\$ 3.8$ trillion in 2016, up from $\$ 3.7$ trillion the previous year. The U. S. market accounts for approximately $28 \%$ of the total, or slightly more than $\$ 1$ trillion.

The IT channel plays an integral role to facilitate the flow of information technology goods and services from producer to customer.

\section{LITERATURE REVIEW}

The present research is an attempt to create awareness among professionals for a formal skill development which can strengthen the ability of decision making. Decision making in the organization is not dependent on any one person rather involves various structures, minds and cultures. To initiate a smooth process in the merger of these an efficient negotiator is of utmost importance. Negotiation basically described by a noted statesman and negotiator Henry Kissinger as, "a process of combining conflicting positions into a common position, under a decision rule of unanimity" (Kissinger, 1969). Elsewhere, theorists have portrayed negotiations as events of diplomatic artistry, mechanical reflections of relative power, and weighted interactions between personality types or rational decision-making processes.

Many negotiators trust their intuition. Much as we might be inclined to view a successful negotiator as one who is naturally gifted, we might also believe that we should privilege our gut feelings when it comes to facing and responding to an opponent negotiator. Keith Stanovich and Richard West (2000) have distinguished between System 1 and System 2 thought, characterizing the former as automatic, effortless, and influenced by emotions, and the latter as conscious, deliberate, and systematic. While we may believe we have control over how we think about situations, when it comes to the most important and complex decisions and negotiations, the limits to our cognitive resources shift us toward System 1 thought. This reliance on intuition that often comes with emotionally charged interactions (Loewenstein 1996) and with time pressure allows for the psychological biases that lead to irrationality, improper weighting of information (Petty and Cacioppo 1986; Petty and Wegner 1999), and sub-optimal outcomes.

The only way that an organization and its employees will know how to negotiate is by training them. Organizations across the globe spend many millions of dollars each year on negotiation training for their employees. This training can be in-house, led by consultants and other experts, or employees can travel to training programs at universities and elsewhere. After engaging in a couple of days of training, employees return to the office and attempt to apply what they learned. Unfortunately, their new knowledge often fails to "stick." They quickly abandon the best practices they learned during negotiation training and replace them with ineffective old habits (Pon staff,https://www.pon.harvard.edu/daily/negotiation-training-daily/negotiation-training-skills/—on September 25th, 2017).

Across the globe, negotiation skill training has become a common activity in managerial life. Organizations often take steps to improve their managers' negotiation skills and their ability to manage other negotiators by enrolling them in 
negotiation skills training programs.

Yet often when these managers return to the office, they fail to thoroughly apply the lessons they've learned to their real-life negotiations. Instead, they tend to fall back on their old habits and end up getting the same subpar results because the negotiation skills training they receive is not structured in a way that encourages managers to question their past practices and replace them with a more effective strategies. In addition, there is more that individual negotiators and their organizations can do to ensure that best practices from negotiation skills training are being applied back at work (Katie Shonk, https://www.pon.harvard.edu/daily/negotiation-training-daily, Harvard. edu. on September 7th, 2017).

\section{OBJECTIVES}

The overall objective of the primary research was to study the effectiveness of negotiation skills training for the software professionals in Indian IT sector. The research will help to

- Determine the level of negotiation skills prior to training

- Feedback on the effect of negotiation skills training

- Review changes in employees' negotiation skills level to determine if the training was effective.

\section{Hypothesis}

There is no significant difference in pre-post training of negotiation skills for software professionals.

\section{Data Collection}

In the present research the target population is the Indian software professionals working in IT industry. The sample was Software professionals who had undergone the assertiveness skills training and was willing to give feedback for the effectiveness of training. For the analysis, data was collected from both primary and secondary sources. 204 questionnaires have been collected from IT companies across India.

The questionnaire was an attempt to study effectiveness of negotiation skills training covering a variety of areas like compromise, self-control, flexibility/adjustability, togetherness, coping with situation and other's opinion. The questionnaire was divided into two sections. The first section consists of eight questions related to personal profile of respondents. Section B consists of 16 statements on assertiveness skills.

All the statements of Section B were evaluated on five point rating scale. There was no right or wrong answer to the statements. The candidate just needed to mark the response which first came to their mind after reading the statement. The ratings were as follows Mostly (M), Often (O), Sometimes (S), Rarely (R) and Never (N). The scale of 1 denoted that the particular emotion or task mentioned in the statement was mostly felt or done by the candidate. Similarly the scale of 2 , 3,4 and 5 meant often, sometimes, rarely and never respectively.

Secondary data is acquired through Newspapers, Periodicals, Industry Publications and other reports of the selected companies of Software Industry in India.

\section{METHODOLOGY}

The Questionnaire was administered on employees and the result collected was then analyzed through Factor analysis. Factor analysis gave four major areas of negotiation skills questions. The six areas came out to be compromise, 
self-control, flexibility/adjustability, togetherness, coping with situation and other's opinion. These questionnaires were assessed on various IT companies:

Table 1: Company Wise Distribution

\begin{tabular}{|c|l|c|c|}
\hline S n & \multicolumn{1}{|c|}{ Company } & N & \% \\
\hline 1 & Atos & 3 & 1.47 \\
\hline 2 & Cignex datamatics & 1 & 0.49 \\
\hline 3 & Cognizant Technical Solution & 15 & 7.35 \\
\hline 4 & CSC & 22 & 10.78 \\
\hline 5 & Dot Square & 13 & 6.37 \\
\hline 6 & IBM & 12 & 5.88 \\
\hline 7 & iGATE Inc & 20 & 9.80 \\
\hline 8 & INFOSYS & 6 & 2.94 \\
\hline 9 & Macfee & 3 & 1.47 \\
\hline 10 & NIIT & 52 & 25.49 \\
\hline 11 & Patni & 10 & 4.90 \\
\hline 12 & Persistent & 3 & 1.47 \\
\hline 13 & Syntel Ltd. & 27 & 13.24 \\
\hline 14 & TCS & 1 & 0.49 \\
\hline 15 & TECH MEHINDRA & 8 & 3.92 \\
\hline 16 & WIPRO & 1 & 3.43 \\
\hline 17 & No Response & $\mathbf{2 0 4}$ & $\mathbf{1 0 0 . 0 0}$ \\
\hline
\end{tabular}

Surveys shows that, CMMI $4 *$ and CMMI $5 *$ levels companies are considered for analysis. More than $90 \%$ candidates are from CMMI 4 and 5 level companies, so that level of training, skills of trainer, quality of training content, methodology used for training are at same level and there is no discrepancy in the standard and quality of the procedure and resources of the training.

WIPRO, Infosys, IBM, TCS, Cognizant and others are trend setting companies of Indian IT sectors having major market share in Software industry. Survey covers service based and product based companies. Above mentioned companies cover all the technology and geographical regions of India.

\section{Factors of Negotiation Skills after Factor Analysis}

- Compromise

- Self- control

- Flexibility/ Adjustability

- Togetherness

- Coping with Situation

- Other's opinion/ Agreement

\section{Factor Analysis - Negotiation Skills}

Factor analysis was applied using principal component analysis method on negotiation skills dimension of communication skill. The varimax rotation was used to rotate the factors. The detailed results are given below.

Overall six components were extracted for negotiation skills dimension explaining $78.10 \%$ of variation in the 
Presentation skills variables. Only those factors were retained whose Eigen values were more than 1.

Table 2: Negotiation Skills Variance Explained

\begin{tabular}{|l|c|c|c|c|c|c|}
\hline \multirow{2}{*}{ Component } & \multicolumn{3}{|c|}{ Initial Eigen values } & \multicolumn{3}{c|}{ Rotation Sums of Squared Loadings } \\
\cline { 2 - 7 } & Total & \% of Variance & Cumulative \% & Total & \% of Variance & Cumulative \% \\
\hline 1 & 4.976 & 24.881 & 24.881 & 4.304 & 21.521 & 21.521 \\
\hline 2 & 3.326 & 16.628 & 41.509 & 2.619 & 13.095 & 34.617 \\
\hline 3 & 2.905 & 14.525 & 56.034 & 2.535 & 12.675 & 47.292 \\
\hline 4 & 1.736 & 8.681 & 64.714 & 2.468 & 12.340 & 59.632 \\
\hline 6 & 1.677 & 8.383 & 73.097 & 2.215 & 11.077 & 70.708 \\
\hline
\end{tabular}

\section{Rotated Component Matrix}

In the following table the extracted component along with the statement and their respective factor loading values are given. The six component / factor extracted were named as - Factor 1 Compromise, Factor $2=$ Self-control, Factor $3=$ Flexibility/ Adjustability, Factor $4=$ Togetherness, Factor $5=$ Coping with the situation and Factor $66=$ Other's opinion/ Agreement. Brief descriptions of these factors are given after this table.

Table 3: Negotiation Skills Rotated Component Matrix

\begin{tabular}{|c|c|c|}
\hline Factor & & Factor Loading \\
\hline \multirow{5}{*}{ 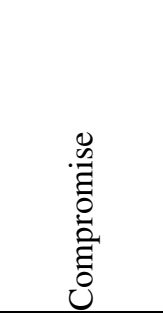 } & Q13_16. I feel people take advantage of me. & 0.925 \\
\hline & $\begin{array}{l}\text { Q13_20. All that matters to me is getting what I want in a deal - it doesn't } \\
\text { matter how. }\end{array}$ & -0.887 \\
\hline & Q13_13. I am a very patient person. & -0.867 \\
\hline & Q13_19. I have no problem with using or manipulating others to get ahead. & -0.852 \\
\hline & Q13_18. Making conversation is something I'm good at. & 0.610 \\
\hline \multirow{3}{*}{ 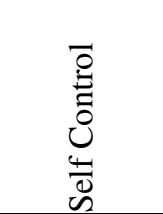 } & Q13_5. I can calm myself down when I'm under stress. & 0.788 \\
\hline & $\begin{array}{l}\text { Q13_8. When preparing for a negotiation, I try to get as much } \\
\text { feedback/advice from outside sources as possible }\end{array}$ & -0.644 \\
\hline & $\begin{array}{l}\text { Q13_1. I am able to resolve problems without losing control of my } \\
\text { emotions. }\end{array}$ & 0.562 \\
\hline \multirow{4}{*}{ 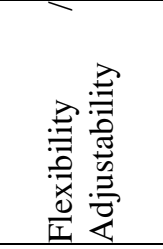 } & $\begin{array}{l}\text { Q13_11. When a situation requires a change of plan or strategy on the spot, } \\
\text { I get flustered/ anxious. }\end{array}$ & -0.695 \\
\hline & Q13_12. I can easily build a good rapport with people. & 0.666 \\
\hline & Q13_15. I am comfortable dealing with conflict when it arises. & 0.644 \\
\hline & Q13_9. In general, when I fail at something, I am devastated. & 0.566 \\
\hline \multirow{3}{*}{ 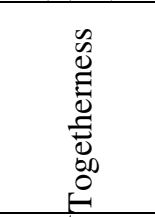 } & $\begin{array}{l}\text { Q13_4. I tend to just go along with what everyone else wants, instead of } \\
\text { stating my own desires. }\end{array}$ & 0.837 \\
\hline & $\begin{array}{l}\text { Q13_3. I will stop a speaker in mid-sentence to interject my opinion if I } \\
\text { disagree with a statement he/she has made. }\end{array}$ & -0.819 \\
\hline & Q13_14. When making a decision, I try to consider all points of view. & 0.799 \\
\hline \multirow{3}{*}{ 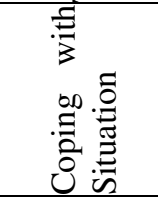 } & Q13_7. When small things go wrong, I become frustrated. & 0.895 \\
\hline & $\begin{array}{l}\text { Q13_10. When faced with a problem, I try to look at it from different } \\
\text { angles in order to come up with the best solution. }\end{array}$ & -0.683 \\
\hline & Q13_6. I find it difficult to function normally when I'm under pressure. & 0.660 \\
\hline \multirow{2}{*}{ 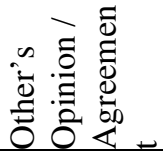 } & $\begin{array}{l}\text { Q13_2. In an argument, I can see things from the other person's point of } \\
\text { view. }\end{array}$ & 0.777 \\
\hline & Q13_17. I carefully consider views that are different from my own. & 0.713 \\
\hline
\end{tabular}


As per the above table the dimensions of negotiation skills are factorized into six factors namely compromise, self-control, flexibility, togetherness, coping with the situation and Agreement.

Compromise: This factor is covered under the statement number 16, 20, 13, 19 and 18. The factor denotes a compromising or in opposite confronting way of dealing with matters while working with someone. The scores in this factor indicates that either the respondent surrenders to other people's wish and other's might take advantage of respondent or the respondent can manipulate the situation or the person to have the things work.

Self-Control: The statements covered in this factor are 1,5 and 8. This shows the control on self under the situation of stress or otherwise. The scores depict either the respondent is able to manage the situations while negotiating or communicating with others in stress by keeping themselves calm, or else on the other extreme might lose control of emotions while handling problems.

Flexibility: This factor covers statements number 9, 11, 12 and 15, which involves both positive and negative frame of statement. The statements indicate the flexibility of respondent dealing with the situation exemplifying, when the circumstance demands change of strategy or plan, dealing with failures or dealing with conflicts when it arises how comfortably it is handled.

Togetherness: This factor incorporates statement number 4, 3 and 14. It emphasizes the team work ability of the respondent. The statements suggest weather the person takes everyone's viewpoint in consideration while handling the negotiating situation puts his or her opinion above the others view.

Coping with Situation: This factor includes statement number 7, 10 and 6. It refers to the ability of the person, to cope with the situation under stress. Score indicates either the respondent slowly hails towards the solution of the problem, or become frustrated when encounter any problem.

Agreement: The factor of Agreement involves statements number 2 and 17. This includes the ability to agree with other's opinion. According to the statements under this factor the respondent either welcomes others viewpoint for a situation and considers others area of interest while taking any decision or is vice-versa.

\section{Post Training Negotiation Skill Analysis}

This data represents the level of candidates in present circumstances on whom the questionnaire is administered. It specifies the employees' negotiation skills level as per the dimension of compromise, self-control, flexibility /adjustability, togetherness, coping with situation and other's opinion at the time of answering questionnaire.

Table 4: Inter-Comparison of Factors-Negotiation

\begin{tabular}{|l|c|c|c|c|c|}
\hline \multicolumn{1}{|c|}{ Factor } & N & Mean & SD & F & Result \\
\hline Compromise & 204 & 3.13 & 0.66 & & \\
\hline Self-Control & 204 & 3.85 & 0.36 & & \\
\hline Flexibility & 204 & 3.31 & 0.49 & \multirow{3}{*}{143.32} & $* * *$ \\
\hline Togetherness & 204 & 3.34 & 0.44 & & \\
\cline { 1 - 4 } Coping with Situation & 204 & 3.28 & 0.48 & & \\
\hline Others' Opinion & 204 & 4.18 & 0.42 & & \\
\hline
\end{tabular}

To see whether there is any significant difference in the factors of negotiation dimension, one way ANOVA was applied. The test result shows highly significant difference $(\mathrm{F}=143.32, \mathrm{p}$ is less than 0.001$)$ between different factors of negotiation skills as measured on the current level of the respondent. Though all the factors showed above average 
effectiveness of training but Opinion from others or agreement with others shows the highest and compromising is the weakest area in comparison to others where the current negotiation skills effectiveness is considered.

Graphical representation of the above score is underneath:

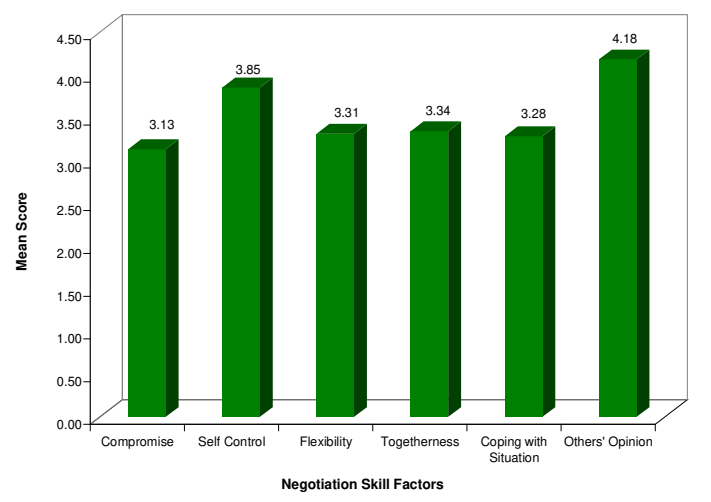

Graph 1: Inter-Comparison of Factors-Negotiation

\section{Negotiation}

$\mathbf{H}_{\mathbf{0 1}}$ : There is no significant difference in the compromise factor of negotiation, between pre-test scores and postscores.

$\mathbf{H}_{\mathbf{0 2}}$ : There is no significant difference in the self-control factor of negotiation, between pre-test scores and postscores.

$\mathbf{H}_{\mathbf{0 3}}$ : There is no significant difference in the flexibility factor of negotiation, between pre-test scores and postscores.

$\mathbf{H}_{\mathbf{0 4}}$ : There is no significant difference in the togetherness factor of negotiation, between pre-test scores and postscores.

$\mathbf{H}_{\mathbf{0 5}}$ : There is no significant difference in the coping with the situation factor of negotiation, between pre-test scores and post-scores.

$\mathbf{H}_{\mathbf{0 6}}$ : There is no significant difference in the other's opinion or agreeableness factor of negotiation, between pretest scores and post-scores.

Table 5: Pre-Post Training Comparison-Negotiation Skills

\begin{tabular}{|c|c|c|c|c|c|c|}
\hline Factors & Period & $\mathbf{N}$ & Mean & SD & $\mathbf{t}$ & Result \\
\hline \multirow{2}{*}{ Compromise } & Pre & 204 & 2.85 & 0.71 & \multirow{2}{*}{-15.72} & \multirow{2}{*}{$* * *$} \\
\hline & Post & 204 & 3.13 & 0.66 & & \\
\hline \multirow{2}{*}{ Self Control } & Pre & 204 & 3.47 & 0.42 & \multirow{2}{*}{-17.99} & \multirow{2}{*}{$* * *$} \\
\hline & Post & 204 & 3.85 & 0.36 & & \\
\hline \multirow{2}{*}{ Flexibility } & Pre & 204 & 3.00 & 0.54 & \multirow{2}{*}{-17.92} & \multirow{2}{*}{$* * *$} \\
\hline & Post & 204 & 3.31 & 0.49 & & \\
\hline \multirow{2}{*}{ Togetherness } & Pre & 204 & 3.04 & 0.48 & \multirow{2}{*}{-19.32} & \multirow{2}{*}{$* * *$} \\
\hline & Post & 204 & 3.34 & 0.44 & & \\
\hline \multirow{2}{*}{ Coping with Situation } & Pre & 204 & 3.00 & 0.52 & \multirow{2}{*}{-16.63} & \multirow{2}{*}{$* * *$} \\
\hline & Post & 204 & 3.28 & 0.48 & & \\
\hline \multirow{2}{*}{ Other's Opinion } & Pre & 204 & 3.79 & 0.50 & \multirow{2}{*}{-18.06} & \multirow{2}{*}{$* * *$} \\
\hline & Post & 204 & 4.18 & 0.42 & & \\
\hline
\end{tabular}


The test result shows highly significant difference in each factor namely compromise $(\mathrm{t}=-15.72$, $\mathrm{p}$ is less than 0.001), self-control $(\mathrm{t}=-17.99$, $\mathrm{p}$ is less than 0.001), flexibility $(\mathrm{t}=-17.92$, $\mathrm{p}$ is less than 0.001$)$, togetherness $(\mathrm{t}=-19.32$, $\mathrm{p}$ is less than 0.001), coping with situation $(\mathrm{t}=16.63$, $\mathrm{p}$ is less than 0.001$)$, other's opinion $(\mathrm{t}=-18.06$, $\mathrm{p}$ is less than 0.001$)$ between pre-test and post-test scores.

Thus all null hypotheses are rejected and it is concluded that there is highly significant difference in pre-test and post-test result in each factor of negotiation skills dimensions. Hence it can be said that there is highly significant effect of communication skills training on negotiation skills dimension.

Graphical representation of the above score is underneath:

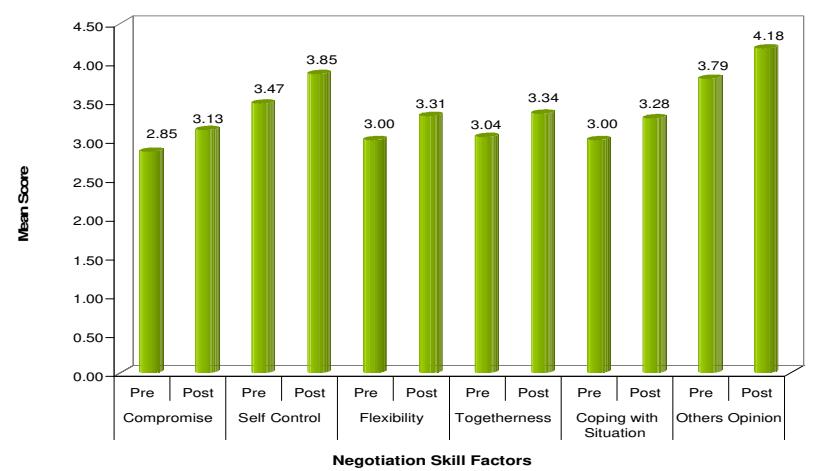

Graph 2: Pre-Post Training Comparison-Negotiation Skills

\section{CONCLUSIONS}

For the dimension of Negotiation skills, mainly respondents stand on higher level and also some stand on medium and few on very high level, in the factors of Compromise, Self-Control, Flexibility, Togetherness, Coping with the situation and Other's opinion. This shows, according to respondents their current status is good in negotiation skills. Analysis of the dimensions of negotiation skills denotes other's opinion or agreeableness, in the factor getting more influenced after the training, in which candidates learn to give value to other's opinion even if, it is different from the viewpoint of self.

After review of previous literature it is observed that, post training feedback analysis and action on the basis of feedback lacks consideration. Companies mainly focus on reaction feedback, but they should also emphasize learning and behavioural feedback, which will show the implication of the training attended. In need assessment procedure HR can also involve manager and consider the profile and academic background of the employees, for understanding the exact requirement of the candidate and the work profile. External researches could be given importance in the companies and the analysis could be used for the betterment of the company procedures. Even research can be done jointly by ensuring company confidentiality instead of restricting the researchers, so that later the results can be beneficial to both researcher and company. As language skills is an undefined prerequisite for such type of trainings, so candidate should try to enhance their language, by doing practice or taking some outside learning source. In another variable of Negotiation skills, the dimension of self-control shows less effect of training, in comparison to other dimensions and other's opinion, which shows greater amount of training effectiveness, as it is difficult to control the emotions and attitude of self, even after learning. This requires self-awareness by employees and the trainer needs to focus on, one to one session, for making trainees effective on this point. 


\section{REFERENCES}

1. Hargie, O., Dickson, D., Tourish, D. (2004) Communication Skills for Effective Management. Palgrave Macmillan. Hampshire.

2. Hartley, P. \& Bruckman, C. G. (2002) Business Communication Route ledge London.

3. Kathryn A. Baker, 2002, Organizational Communication

4. Katzenbach, J. R., and Smith, D. K. (1992) Wisdom of teams, Harvard Business School Press.

5. Kavita Gupta, 2007, A Practical Guide to Needs Assessment.

6. Ken Kragen, INTERPERSONAL COMMUNICATION: A First Look.

7. Kilmann, R. H. Thomas-Kilmann Conflict Mode Instrument. [Online] Available: http://www. kilmann. com/conflict. html (June 16th, 2010)

8. LaFasto, M. J. F., \& Larson, C. (2001). When teams work best: 6,000 team members and leaders tell what it takes to succeed. Thousand Oaks, CA: Sage.

9. O'Brian, James. “Introduction to Information Systems”, Irwin Book Team, $8^{\text {th }}$ edition, (1997).

10. Organizational Communication for Survival: Making Work, Work. Richmond, McCroskey, \& McCroskey (2005).

11. Paulsel, M. L., \& Mottet, T. P. (2004). Interpersonal communication motives: A communibiological perspective. Communication Quarterly.

12. Peters, T., \& Waterman, R. (1982). In search of excellence. New York: Harper \& Row.

13. McConnell, John H. How to identify your organization's training needs: a practical guide to needs analysis, 2003, ISBN 08144-0710-2 published by Library of Congress Cataloguing.

14. NAWA Journal of Language and Communication, June 2008, The Importance of Soft Skills: Education beyond academic knowledge, Bernd Schulz, Polytechnic of Namibia.

15. http://www. globalization101 . org/information-technology/

16. http://web. stanford. edu/group/scip/avsgt/Dave_thesis. pdf

17. http://en. wikipedia.org/wiki/Information_technology_in_India

18. http://rbi. org. in/scripts/BS_PressReleaseDisplay. aspx?prid=29029

19. Pon staff, https://www. pon. harvard. edu/daily/negotiation-training-daily/negotiation-training-skills/ - on september 25th, 2017

20. Katie Shonk, https://www. pon. harvard. edu/daily/negotiation-training-daily, Harvard. edu., on September 7th, 2017 